OPEN ACCESS

Edited by:

Whitney Sherman Newcomb, Virginia Commonwealth University,

United States

Reviewed by:

Sarina Chugani Molina, University of San Diego, United States

Eva Matthes,

University of Augsburg, Germany

*Correspondence:

Claudia Fahrenwald

claudia.fahrenwald@ph-ooe.at

Specialty section:

This article was submitted to

Leadership in Education, a section of the journal

Frontiers in Education

Received: 07 November 2017 Accepted: 12 January 2018

Published: 31 January 2018

Citation:

de Boer $\mathrm{H}$, Fahrenwald $\mathrm{C}$ and Spies A (2018) Professionalization in

Teacher Education As an

Interorganizational Learning

Challenge.

Front. Educ. 3:4.

doi: 10.3389/feduc.2018.00004

\section{Professionalization in Teacher Education As an Interorganizational Learning Challenge}

\author{
Heike de Boer ${ }^{1}$, Claudia Fahrenwald ${ }^{2 *}$ and Anke Spies ${ }^{3}$ \\ ${ }^{1}$ Campus Koblenz, University of Koblenz and Landau, Koblenz, Germany, ${ }^{2}$ University of Education Upper Austria, Linz, \\ Austria, ${ }^{3}$ University of Oldenburg, Oldenburg, Germany
}

Cultural and social changes, new administrative regulations, and curricular reforms have had a significant impact on the work and professional self-image of future teachers in many European countries involved in the Bologna Process. This constellation gives rise to new challenges for established routines, practices, and identities of the organizations involved in teacher education. This article deals with processes of professionalization in teacher education and presents new forms of interorganizational cooperation between schools, universities, education authorities, and extracurricular agencies. Three case studies from Germany and Austria clearly demonstrate that different organizational cultures as well as different professional self-images meet in cooperative environments. The goal of the article was to analyze systematically the various interorganizational learning challenges in the field of teacher education.

Keywords: cultural and social change, international teacher education, professionalization in teacher education, organizational cultures, interorganizational cooperation

Against the backdrop of societal transformation, ministerial guidelines, and curricular reforms, entirely new demands have been placed on the type of work undertaken by and the professional self-image of future teachers in many European countries as a result of the Bologna Process. The Bologna Process is a series of ministerial meetings and agreements between European countries to ensure comparability in the standards and quality of higher-education qualifications. These challenges have also had an impact on the established routines, practices, and identities of the organizations involved in training. This article addresses issues of professionalization in teacher education, using the example of new forms of interorganizational cooperation between schools, universities, educational authorities, and extracurricular agencies in Germany and Austria. Heike de Boer starts by presenting the research at the Koblenz primary schools and teacher education colleges network. She discusses the different expectations, professional cultures, and reinterpretation of educational policy guidelines in the various organizations. Anke Spies then describes the demands placed on pedagogical professional development as a result of municipal educational landscapes in which primary schools and youth welfare organizations cooperate to provide all-day schooling. Finally, Claudia Fahrenwald discusses the introduction of an "extended field of practice" in Austrian teacher education, which is linked to a new professional understanding of the future roles of future teachers as well as new forms of cooperation between universities, schools, and extracurricular cooperation partners. The aim of the article is to analyze systematically the interorganizational learning challenges within the context of practical teacher education. 


\section{COOPERATION AND NETWORKING AS A REFORM STRATEGY FOR TEACHER EDUCATION}

In recent years, cooperation and networking have become key reform strategies for teacher education. These strategies have been introduced as part of educational policy and educational administrative initiatives designed to establish new learning cultures in schools (Rürup et al., 2015). The strategies concern partnerships between schools as well as new forms of cooperation between schools and extracurricular agencies and reflect the hope that cross-institutional cooperation will promote school development and play a role in teacher education (Berkemeyer and Järvinen, 2011). Ministerial steering measures must be reinterpreted to reflect the changing situation, and the established working cultures of the participating organizations, all of which are different, and their collectively shared assumptions and practices must be reassessed. In this context, Weick and Sutcliff (2010) (p. 122) referred to the "culture of an organization" as a way of dealing with expectations, which can be understood as silent agreements on appropriate attitudes and behaviors, and often remain implicit. Organizations therefore represent social structures, cultural patterns, or even symbolic orders (Weber et al., 2014), which are particularly pronounced in the context of change processes. This perspective is also essential for cooperation between organizations. In the following sections, we ask which assumptions, ideas, and values are addressed by the individual participants in the cooperation between the various organizations participating in practical teacher training. In addition, we discuss the role of ministerial steering measures.

Three empirical, qualitative case studies discuss through case analysis and cross-case analysis learning challenges associated with these new forms of interorganizational cooperation in various pedagogical settings. We focus on three different forms of cooperation in the context of teacher education:

- Case study 1: Cooperation between teacher training at the university and outside the university during the in-service training supervised by a teacher training college.

- Case study 2: Cooperation between schools and the youth welfare.

- Case study 3: Cooperation between university, schools, and different "extended fields of practice."

The data of the first case study are based on eight group discussions between teachers of the university and teachers of the inservice training outside of the university. The group discussions were transcribed and analyzed by the method of content analysis (Mayring, 2012).

The second case study follows an evaluation order by school. In two steps, this case study combines qualitative research methods: first data were collected by group discussions and analyzed by using SWOT Evaluation to get the initial situation. Based on the findings, the second step reconstructed the development and the perspectives on interactions in the first year working side by side by using problem-focused, semistructured interviews.
The third case study is based on formative and summative evaluation following an exploratory and multiperspective approach. The methodology included both the analysis of existing documentation and the collection of ethnographical data based on transcripts of group discussions, photos, and testimonies. The rationale behind connecting the various steps of enquiry was to document and reflect upon the learning experiences of and challenges faced by the various actors involved in the project. For all data pseudonyms have been used.

Our findings made it clear that there is a real clash between the different organizational cultures and professional selfperceptions, whereby the various actors have considerably different understandings of communication, cooperation and professionalization. The first case study deals with interorganizational cooperation between universities and teacher education colleges.

\section{INTERORGANIZATIONAL COOPERATION BETWEEN UNIVERSITIES AND TEACHER EDUCATION COLLEGES}

I sometimes really worry that this transition just isn't working at all, because you just don't have a clear idea of what's going on. What do they [second phase of teacher education college] actually want from you ...

This quotation from a trainee highlights the fact that the integration of the various phases of teacher education is absolutely essential for providing effective teacher education, which is a dual system (involving both theoretical and practical elements) in Germany. Numerous empirical studies confirm this statement (e.g., Hascher, 2011; Schuberth et al., 2011; Bosse et al., 2012). Yet in Rhineland-Palatinate, a federal state in Germany, the teacher education colleges are responsible for not only the content and structure of the second phase but also the implementation of and provision of support for the advanced work placement in schools. Around 10 years ago the placements used to be affiliated with universities, which also offered preparatory and follow-up courses for those placements. Nowadays, however, supervision and support during the placements are provided entirely by the school mentors and heads of departments at teacher education colleges. The trainees are no longer offered any accompanying courses from the universities. All people involved in the system need to find a better way to combine the three elements: the university, the teacher education college, and the advanced work placement. In the following section, we present the results from the accompanying research.

\section{The Koblenz Network of Primary Schools and Teacher Education Colleges}

The Koblenz network of primary schools and teacher education colleges [Koblenzer Netzwerk Campusgrundschulen und Studienseminare (KONECS)] aims to promote intensive cooperation between institutions involved in primary school education in order to develop greater continuity among the content provided during the different phases of teacher education. 
Systematic integration of the theoretical educational programs, empirical research, and cooperation with schools and teacher education colleges constitutes an attempt to develop an overall strategy for the education network. Schools are supervised by the school inspectorate and the ministry; heads of department also fall under the direct responsibility of the ministry. Both are embedded in a strictly hierarchical system. Universities, on the other hand, operate on the same level as the ministry and do not have a dependent or employee-employer relationship with the ministry. The interorganizational cooperation studied can be described as a "vertical network" in the sense of what Weick termed a "loosely coupled system" with "weak ties" (Weick, 1979): a decentralized network, in which the participating organizations maintain their profile and institutional identity throughout the cooperation. In traditional network phase terminology, the project carried out during our research was in the development phase (ibid., 141), during which close links are forged between theory and practice. KONECS tries to respond to the need to improve integration between the different phases of teacher education and offers a conceptual solution, whereby:

- connections are forged along pedagogic-didactic issues at the interface between work at the school and university assignments.

- research and reflexive learning are established systematically.

- contact with the second phase of teacher education becomes more intensive, since joint training courses on the key issues of teacher education every semester by heads of departments, mentors, and lecturers of the Institute for Primary School Education and academic support are provided for the trainees.

\section{Key Results of Research Conducted}

In the 2013 summer semester, eight group discussions were held with lecturers and teachers of students-teachers at two conferences. The purpose of these discussions was to reconstruct the heads of departments' views on "pedagogical observation." The issue of "observed learning" in the BEd Primary School Education was introduced during a presentation at a conference held at the University of Koblenz, and examples were used to illustrate how trainees become aware of the need to observe pupils' performance and behavior in specific subject-related teaching situations in a process-oriented and in-depth way. After the introduction to the topic, heads of department were asked if they saw any substantive connections, and if so, where. From the group discussions it became clear that the majority believed that the topic fits best in the initial and advanced work placements.

However, it was also noted that there were many different interpretations of the term "observation." The majority understood it to have broadly the same meaning provided in the criteria for "good teaching" in the "Rhineland-Palatinate Framework for School Quality" (ORS). These criteria are used to assess the planning, reflection upon, and observation of lessons. In the following quotation, a department head recognizes that there is common ground in "observation" work, yet at the same time makes a clear distinction:
I also think that our observation assignments in the teacher-training courses seem to be going in a very different direction at the moment. They are more focused on and restricted to the terms found in the Framework for School Quality, which now have little to do with professional problems based on professional perspectives or substantive issues, because (...) we are instructed to provide skills-based training and that usually means that we say we have guidelines to help us. These are things like stimulation, motivation, an emphasis on skills... structuring the content (...). (Lanzer, BG-011)

Here, a very clear, collective "we" is constructed, because all heads of departments are obliged by the ministry to work according to the "Framework for School Quality" (ORS). The passive phrase "we are instructed" refers to the ministry as the employer of all heads of departments. It is interesting that the department head creates a dichotomy between professionalism and an emphasis on skills. The "guideline" criteria are those terms which are specified and measured in the ORS, while the "things" considered to be key, such as stimulation, motivation, and emphasis on skills and structure, are understood to be more methodological than professional. The concepts, the premises on which they are based and the accompanying implications were not further addressed in the group discussions. The use of the term "guidelines" points to simultaneous observation and evaluation based on the terms, because "guideline" refers back to a benchmark which suggests a static measurement. Lessons are observed and evaluated immediately, in a way similar to the way in which external quality audits are conducted. Here, there is a clear and significant difference between learning process observations, which focus explicitly on the documentation of process-related actions and systematically differentiate between description and evaluation (de Boer, 2012, 75 ff.).

\section{Reinterpretation of Ministerial Orders As a Collective Development Task?}

In this first phase of the approach, the department heads assessed the information provided during the conference against their everyday experience. Even if they appreciate that there is a substantive link to pedagogic observation, the participants from the teacher education colleges and the universities have contradicting views and expectations. Department heads assess pedagogical observation in terms of the extent to which it can be connected to measures introduced by the ministry and builds upon concepts outlined in the ORS, educational standards, or subframework plans (de Boer, 2015). Their expectations are shaped and modified by the organizational context of the teacher education colleges, which are under the direct authority of the ministry. In this view, process-oriented learning observation corresponds neither to the standard or skills-oriented categories listed in the subframework plans nor to the categories listed in the Framework for School Quality prescribed by the ministry. Participants from teacher education colleges discussed the consequences of integrating content and examined the extent 
to which the topic fits into their field of work, i.e., they looked for synergies without having to include additional topics. After sharing and reflecting on the issues in the discussion, a few of the groups began to develop new perspectives which allowed them to identify the differences between teaching and learning process observations and which address the significance of a conscious and deliberated separation of observation, description, and evaluation for observations on process and potential.

This shows that significant challenges lie ahead for organizations trying to forge partnerships in which the organizations aim to develop connections and play a role in providing the content. These challenges include:

- All parties having a mutual and equal right to set the central assignments.

- There must be a joint discussion of important terms for the respective working context.

- Organizations need to look for overarching themes and opportunities.

- They also need to work on developing synergies for defining common targets.

In light of current ministerial measures regarding the education system, it is also important that the organizations involved deal with the reinterpretation process together. Throughout this process, professionals from the teacher education colleges and universities encounter the established, diverse cultures of the participating organizations as well as their collectively shared interpretations and ideas. University staff are guided by the maxim of "freedom of research and teaching" and they interpret ministerial regulations quite openly but, by contrast, staff from teacher education colleges understand the regulations to be compulsory and feel obliged to implement them fully. In the development phase of the network, it is therefore important to understand the different perspectives, to respect and recognize them, and to work together through discussion. The challenge for all people involved is not to devalue the "artifacts," "assumptions," and "beliefs" of "foreign organizations," but to search for common ground (de Boer, 2015). This presupposes a high degree of openness and willingness for interorganizational and intraorganizational communication and cooperation between individual organizations. The second case study addresses interorganizational cooperation between universities and social work.

\section{INTERORGANIZATIONAL COOPERATION BETWEEN PRIMARY SCHOOLS AND YOUTH WELFARE ORGANIZATIONS}

\section{Between Administrative Requirements and Professional Differences}

New decrees issued by school authorities are intended to promote schools' autonomy, improve its integration in society, and change organizational conditions. On the other hand, municipal education planning (BMFSFJ Federal Ministry for Family Affairs, Senior Citizens, Women and Youth, 2005) encourages municipal and independent providers of youth welfare services to take on an effective role in the conceptualization of the school development process (Spies, 2018). Thus, we are currently seeing contradictory requirements being made of all-day school settings due to educational and sociopolitical measures. Schools and youth welfare organizations each have to deal with the professional habits of the other. Expectations differ, common pedagogical concepts lead to marginal shifts in spheres of activity, responsibilities are questioned, and professional assessments of needs follow different maxims of pedagogical self-image (Spies, 2016).

In another German federal state (Lower Saxony), one variant of interorganizational cooperation is the collaboration between a primary school and the former provider of after-school activities (independent organizations which provide youth welfare services). In the framework of a municipal plan for cooperative, all-day primary schools (public and partially affiliated), these organizations have been joined to form a new organization. Institutional disorder is thrown into the spotlight during this process. It serves as evidence for theoretical and practiceoriented analyses of professional development (Dick, 2016), as well as grounds for reflection on different understandings of professionalization (Braun, 2015) and the requirements for (primary) school development involving trainees in the first phase of teacher education (Gerheim and Spies, 2017). The learning challenges within interorganizational cooperation make it increasingly clear that social context contributes significantly to professional self-image throughout teacher education. Tensions between sociopedagogical and school-pedagogical expertise highlight social needs that appear to contradict professional knowledge (Dick, 2016). Administrative constraints, diverging self-perceptions, and the divergence of the scope of their activities (Heinrich et al., 2014) demand of the cooperation partners that they redefine their task profiles and reexamine their professional self-image (Spies, 2016).

\section{Process Support}

For the professionals, interorganizational cooperation in practice means engaging in negotiations to define and divide tasks and develop participatory structures. Cooperation is therefore a long-term organizational and professional development task, which should result in a shift from a tradition of professional differences to more professional recognition (Idel, 2016). School-based research provides insights into the process characteristics and complexity involved in the joint development of pedagogical concepts. In order to determine the starting point for cooperation between primary school teacher education colleges and youth welfare agency employees, two separate group discussion transcripts (Loos and Schäffer, 2001) and strengthweakness data from two other separate sessions were evaluated with SWOT analysis (Künzli, 2012). All professionals involved in the development and cooperation process had the opportunity to explain their assessment of the conceptual framework as well as the short-term and medium-term opportunities and risks. Subsequently, the first year of cooperation was analyzed based on information collected during eight problem-focused, guided interviews (Witzel, 2000) with 11 teachers (three groupinterviews with two teachers each), four sociopedagogical 
professionals from independent youth welfare agencies and the senior management (school management or team leaders). The focus was on cooperative relationships and professional self-perceptions, in order to reconstruct the all-day concept analytically (Mayring, 2012). The findings were discussed as development impulses with the groups of professionals and gave the trainees involved an insight into the current challenges for the development of the school organization.

\section{Administrative and Educational Contradictions}

The analysis of the starting point for cooperation clearly shows that the people involved perceive the situation to be problematic. They hardly focus on strengths and opportunities; they are primarily concerned with the difficulties and risks of organizational cooperation. Although they appreciate the benefits for staff and the fact that they have a better understanding of others' perspectives, all interviewees emphasized gaps in the communication structure. School regulations run counter to municipal directives and result in different understandings of the cooperative relationship. Conceptual requirements and gaps in the concept, which only become visible during implementation, show interactions between professional self-perception and high expectations (the momentum for which is maintained by the individuals themselves) regarding the educational opportunities of cooperation posited by the administration. The realization of the cooperative partnership is impeded by competing pedagogical maxims deriving from the traditions of the respective spheres. The development of a shared organizational culture with some room for maneuver, therefore, requires an examination of the different administrative and professional interpretations, since it cannot be assumed that all the people involved share the same assumptions.

\section{New Task Profiles}

Measures to establish cooperative partnerships-joint measures as well as those introduced by schools and other agencies-confirm that new task profiles are indeed emerging [as analyzed by Gängler et al. (2013)]. Youth services are currently being confronted with this change: decisions made by municipal for schools and youth welfare services regarding the structure of education impose the school setting on after-school activities (Spies, 2017, 2018). This process is accompanied by irritations regarding the professional self-image and the perceived undervaluing of professional sociopedagogical skills. This results in passive acquiescence of after-school education professionals, who now have to make their professional pedagogic contribution to the interorganizational cooperation in a school environment. On the other hand, the cooperation increases the scope of action for school-pedagogical professionals, who can decide whether and to what extent they want to use the maxims of youth welfare to reflect upon their own professional attitudes. If this benefit is construed as a rapprochement and expansion of professional skills, it appears that the gains from interorganizational cooperation are unilateral, since a general acknowledgment of socio-pedagogical professionalism is lacking.
The relationship of interaction is contingent on preserving the symbolic order and the social structures of demarcation. Approaches to creating connections between the content of after-school activities and lessons at school lead to changes in the evaluation of creative and cognitive content in those lessons. Teachers delegate the encouragement of creative interests to the sociopedagogical professionals and increase the share of activities that promote cognitive development, thereby limiting their own task profile. Understanding the relationship to be hierarchical, they expect assistance in the fulfillment of school expectations. Unlike for sociopedagogical professionals, interactions which are necessary for designing cooperative partnerships, such as professional communication and microstructural organization, do not (yet) form part of the school teachers' official range of tasks. Instead, these were performed on a voluntary basis. In reality, a symbolic, hierarchical professional self-perception underlies cooperative relationships. For example, if a colleague refers to "quality differences" (I 4, section 46) and mentions that she "has to have a meeting" (I 4, section 46) with "my after-school staff" (I 4, section 45) in order to give instructions, she devalues the professional expertise of the sociopedagogical colleagues. They do not plan or conceive activities based on their professionalism, but "just think something up," "spend time with the children," and "try to adjust their activities to fit the respective group" (I 4, section 36). This indicates that delegation and differentiation are (necessary) intermediate stages on the way to establishing relationships with colleagues in which differences are recognized and appreciated (Idel, 2016). Administrative requirements constitute an obstacle which can consolidate competing professional self-perceptions, since an "understanding of collaborative professionalism within a network" (Idel, 2016) can be expected to be based on numerous preconditions and is by no means an automatic, natural development. Stages in the development process, such as professionals establishing their "position in terms of professional-specific competences and responsibilities" (Reh and Breuer, 2012), require a structural framework within the interorganizational cooperation so that different professional self-perceptions (can) lead to shared assumptions.

\section{INTERORGANIZATIONAL COOPERATION BETWEEN UNIVERSITIES, SCHOOLS, AND EXTRACURRICULAR DOMAINS}

Finally, the third case study concerns new forms of cooperation universities, schools, and extracurricular domains, which were recently introduced at the University of Education Upper Austria, Linz (Austria). In Austria, teacher education has been undergoing substantial reform as part of the new educational policy initiative (PädagogInnenbildung Neu). One of the aims of this initiative is to redesign and expand vocational professionalization processes (BMUKK Federal Ministry for Education, Art and Culture, 2010).

\section{The Introduction of an "Extended Field of Practice"}

If we assume that a school's educational tasks change as a result of cultural heterogeneity, social inequality, and increasing 
individualization, it is only logical that guidance and support for pupils should be provided in an overall context which also integrates extracurricular learning centers and settings. With this in mind, an "extended field of practice" was introduced, on a mandatory basis, for all trainees at the University of Education Upper Austria. This refers to work placements that take place in non-traditional teaching settings (e.g., in social institutions, after-school centers, out-of-school tutor groups, and cultural associations) or at regular schools but with a focus on environments and issues outside the classroom (e.g., learning or pedagogical support). In this way, trainees come to understand that the school is an integral part of society, i.e., a place which directly mirrors developments and realities in society. Working with children and adolescents outside school or outside their regular teaching duties enables the teachers to gain a deeper understanding of the different concepts of life, living conditions, and life histories. The fundamental idea behind the project is that these work placements offer trainees the opportunity to gather other teaching experiences in addition to traditional teaching experience in the classroom (Prammer-Semmler, 2013). This implies that there needs to be a review of professional self-image as part of the training and that it is connected to new interorganizational learning challenges for the organizations involved, which so far tend to have acted independently.

\section{Learning Locations and Learning Content of the "Extended Field of Practice"}

In the following section, we discuss the places of learning and learning content which may form part of the extended field of practice in order to clarify the conceptual and organizational changes in conventional practice in schools. Here, for example, places of learning can be after-school care groups at schools or centers, the role of "assistants" in school classes, learning support for individual pupils with or without a migration background, or the supervision of leisure activities for pupils (Compendium Schulpraktische Studien, 2013). Trainees work at schools or extracurricular institutions and take on educational activities, such as supporting fulltime pedagogues or designing and implementing recreational projects. During the relevant courses with the university mentor, it is essential that trainees' individual experiences are reflected upon and discussed. Since the "extended field of practice" does not concern traditional teaching activities, and therefore, does not concern traditional professionalization processes for the trainees, the mentors are also confronted with new learning challenges. This also applies to extracurricular institutions. For them, mentoring a future teacher is a new experience, which was previously neither addressed by individual nor organizational professional self-image.

\section{Selected Evaluation Results}

In the pilot phase in the 2013/14 winter semester, the research into school practices was adapted in light of the introduction of the extended field of practice. It now included 120 trainees who were studying to be teachers at primary schools (Volksschule, VL), special needs schools (Sonderschule, SL), and new secondary schools (Neue Mittelschule, NMS) as well as 52 extracurricular institutions and schools that primarily focus on other activities.
In the 2014 summer semester, 160 trainees and 117 institutions took part in the study. An element of academic monitoring, based on formative and summative evaluations, was added to the project in order to ensure quality. Due to the nature of the pilot phase, an exploratory and multiperspective approach was chosen. The methodology included both the analysis of existing documentation as well as the collection of ethnographical data based on transcripts of group discussions as well as photos and testimonies. The rationale behind connecting the various steps of enquiry was to document and reflect upon the learning experiences of and challenges faced by the various actors involved in the introduction of the extended field of practice (trainees, mentors, and organizations that offer work placements) (Fahrenwald, 2017). Selected evaluation results are presented below.

Participants in the study reported initial difficulties with both the organization and content: at the start of the work placement, the university was critical of the lack of information concerning the content requirements for the expanded field of practice. Depending on the training program, there were also prejudices against the different types of schools. Trainees valued the fact that they were given the opportunity to choose where they did their placement and that there was a good degree of flexibility when it came to organize their time and the associated responsibilities. On the other hand, "excessive demands" on the trainees as a result of the new freedom and the associated need to set their own boundaries was considered a negative aspect, especially by the mentors. Since the activities in the extended field of practice primarily concerned special education, the trainees occasionally experienced those activities as "pushing the limits" in terms of their own understanding of the profession, e.g., conflicts within families with children with learning difficulties. Many also had fundamental concerns regarding the distinction between activities in the extended field of practice and "normal practice" and whether school practice was being left behind.

Essentially, however, the trainees thought that the extended field of practice allowed them to have a "different type of access to children" and "build relationships." The high level of selfcommitment, spontaneity, and motivating insights into activities other than teaching were also positively received. For many trainees, these experiences also seem to have been beneficial for classroom teaching as well as in building relationships of trust with the children. At the after-school centers, trainees were positive about observing everyday life, daily routines, homework, and after-school care. The trainees appreciated being able to practice dealing with children "without pressure" and have come to know the centers as a "positive, open concept" in which the children have the freedom to decide a lot for themselves. According to the organizations which offer work placements, working and participating at an after-school center give trainees a chance to develop an outsiders' perspective of schools and benefit from having a wider picture of children's lives and learning processes as well as the sustainability of learning (e.g., "What did the children do in the morning? Do they remember what they were taught yesterday?") At the same time, they complained that both the teachers and trainees knew little about the centers' activities. This assessment coincides with the negative feedback from many trainees who completed work placements at centers, who complained about the lack of challenges. The following statement given by a trainee 
is a classic example of this criticism: "I want to be a teacher, not a supervisor in the afternoon."

In retrospect, however, in the extended field of practice trainees who completed their work placements at these centers thought they were "great" for their own professional development. They thought these centers allowed them to gather a broad range of experiences, they got to learn about other areas of education, and felt "empowered" and "well prepared" for their own professional field. Getting to know and learning how to work with different age groups increases the chance that trainees will specialize in the "right age group" during their studies. However, trainees pointed out that the extended field of practice, despite it delivering exciting new experiences, would lead to a reduction of the amount of time they spent teaching. Subsequently, they thought that this had a negative impact on their professional development. Many trainees wanted to spend more time at school and complete the extended field of practice element as an additional assignment. It seems that the universities still have a lot of work to do when it comes to clarifying and convincing those involved of the purpose of the extended field of practice.

\section{CONCLUSION AND OUTLOOK}

The article shows in three case studies that an up-to-date teacher education needs a close cooperation of different organizationsuniversities, teacher education colleges, youth welfare organizations, and extracurricular institutions, but that these necessary cooperation and networking processes are difficult because of the different cultures and concepts of these organizations which often do not fit together, so that a lot of communication is needed to initiate helpful adaptation processes and mutual understanding with lasting differences. Regional educational landscapes are changing the focus of school development and school networks. This creates a "capacity for change" at the horizontal level (Brühlmann and Rolff, 2015). As the three examples of new forms of cooperation and networking show, in the context of practical teacher training, this development is associated with a series of interorganizational learning challenges that should be reorganized and re-evaluated.

Administrative measures, changes to the curriculum, or the development of the "educational landscape" has the potential to cause considerable problems, since the organizational identity of the organizations involved and the self-image of the professionals involved are challenged by the expectations associated with the assumed innovation. The case studies show that models of interorganizational cooperation initiate complex interaction processes, the implicit expectations of which need to be analyzed. Such processes also require an overall strategy, both from a professional and organizational standpoint. The position of mutual recognition developed by Idel (2016) offers an unquestionably demanding but also sustainable approach to expected differences in assumptions, ideas, and values.

If the common goal is to develop new organizational-cultural practices and artifacts, ministerial and administrative measures must be questioned-as should the self-image of the professionals involved. However, the learning challenges and organizational change processes associated with interorganizational cooperation also give rise to basic requirements for teacher education beyond the respective settings. The case studies show that, in a cooperative partnership, different organizational cultures as well as different professional self-perceptions converge, which can by no means be based on tacit agreements and shared assumptions. Just as the fulfillment of ministerial requirements and the freedom of university teaching require a vulnerable process of understanding, cooperative concepts also need to be questioned, provided they reproduce understandings of cooperation that partially challenge the pedagogical competence of a cooperation partner. The divergence in the understanding of the tasks, which was demonstrated in the reconstruction of interactions within the cooperation, is remarkably similar to the trainees' assessment that practical experience in after-school environments contributes very little to their professional development. The latter (in a completely different cooperation setting) reproduce the attitudes of teachers at supplementary all-day primary schools, who demand that their interpretations take precedence (Reh and Breuer, 2012) and tend to ignore the maxims of after-school education.

According to various empirical studies, the devaluation of other professions cooperating with schools seems to occur quite regularly (e.g., Reh and Breuer, 2012; Böhm-Kasper et al., 2013), while improved cooperation between the various organizations is essential for responding to societal change. It would therefore seem necessary to develop a professional habitus, which-in keeping with the development of the educational landscape-no longer relies on competences, but on common "responsibilities" (German Association of Cities and Towns, 2007) of different organizations and (in principle) additional professions. In the context of teacher education, both extended fields of practice and different types of cooperation between schools and youth welfare services (which affect school practice) need to be explained in such a way that conflicts due to irritations, coping with uncertainties, and position-taking vis-à-vis diverging guidelines can be understood as part of the professionalization process. The practical experience of teaching and observing, intensive insights into pedagogic activities beyond their institutional affiliation with the school, and the theoretical and empirical analysis of the changing job profiles and organizational development processes provide trainees with their first practical experiences at a school. The contribution of these experiences to the development of professionalism in teacher education and the professional processing of social change has been empirically proven (Cramer, 2012, 527). Contributions made by universities to the groundwork for future interorganizational cooperation are many and varied and include measures for the establishment of a consultation and support system for the development of new networks (Rürup et al., 2015, 162).

\section{AUTHOR NOTE}

We are a team of three researchers from Austria and Germany presenting three different case studies from our universities: $\mathrm{HB}$, $\mathrm{CF}$, and AS.

\section{AUTHOR CONTRIBUTIONS}

All authors listed have made a substantial, direct and intellectual contribution to the work, and approved it for publication. 


\section{REFERENCES}

Berkemeyer, N., and Järvinen, H. (eds). (2011). Lernen in Netzwerken. J. Schulentwickl. 15, 4-7.

BMFSFJ Federal Ministry for Family Affairs, Senior Citizens, Women and Youth. (ed.). (2005). 12. Kinder- und Jugendbericht. Bericht über die Lebenssituation junger Menschen und die Leistungen der Kinder- und Jugendhilfe. Available at: www.bmfsfj.de/doku/Publikationen/kjb/data/download/kjb_060228_ak3.pdf

BMUKK Federal Ministry for Education, Art and Culture. (ed.). (2010). LehrerInnenbildung NEU. Die Zukunft der pädagogischen Berufe. Die Empfehlungen der ExpertInnengruppe. Final Report. Available at: http://www.qsr.or.at/ dokumente/1870-20140529-092820-Empfehlungen_der_ExpertInnengruppe Endbericht_092010_2_Auflage.pdf

Böhm-Kasper, O., Dizinger, V., and Heitmann, V. (2013). Interprofessionelle Kooperation an offenen und gebundenen Ganztagsgrundschulen. Z. Grundschulfors. 6, 53-68.

Bosse, D., Criblez, L., and Hascher, T. (eds). (2012). Reform der Lehrerbildung in Deutschland, Österreich und der Schweiz. Immenhausen: Prolog Publishing.

Braun, J. (ed.). (2015). Pädagogik im Museum: Eine Untersuchung zum Professionsverständnis aus der Perspektive museumspädagogischer Fachkräfte in Kunstmuseen Museum. Available at: http://d-nb.info/1073247384/34

Brühlmann, J., and Rolff, H.-G. (eds). (2015). Horizontale Schulentwicklung. J. Schulentwickl. 19, 4-7.

Compendium Schulpraktische Studien. (ed.). (2013). Erweiterte Praxisfelder. Linz, Austria: University of Education Upper Austria.

Cramer, C. (2012). Entwicklung von Professionalität in der Lehrerbildung: Empirische Befunde zu Eingangsbedingungen, Prozessmerkmalen und Ausbildungserfahrungen Lehramtsstudierender. Bad Heilbrunn: Klinkhardt.

de Boer, H. (2012). "Pädagogische Beobachtung," in Beobachtung in der Schule. Beobachten lernen, eds H. de Boer and S. Reh (Wiesbaden: Springer VS), 65-80.

de Boer, H. (2015). “Beobachten lernen - Lernen beobachten: Phasenübergreifendes Professionalisieren für inklusive Praxis," in Inklusion und Übergang, eds M. Urban, M. Schulz, K. Meser, and S. Thoms (Bad Heilbrunn: Klinkhardt), $198-217$.

Dick, M. (2016). "Professionsentwicklung als Forschungs- und Handlungsfeld," in Handbuch Professionsentwicklung, eds M. Dick, W. Marotzki, and H. Mieg (Bad Heilbrunn: Klinkhardt), 9-24.

Fahrenwald, C. (2017). "Die Einführung eines erweiterten Praxisfeldes im Rahmen der schulpraktischen Ausbildung an der Pädagogischen Hochschule Oberösterreich," in Forschungsperspektiven Band 9, eds C. Fridrich, G. MayerFrühwirth, R. Potzmann, W. Greller Renate, and R. Petz (Münster, Wien: LIT Verlag S), 241-257.

Gängler, H., Weinhold, K., and Markert, T. (2013). Miteinander? Nebeneinander? Durcheinander? Der Hort im Sog der Ganztagsschule. Neue Praxis 2, 154-175.

Gerheim, U., and Spies, A. (eds). (2017). Forschendes Lernen in der Lehrer ${ }^{*}$ innenbildung. Ein hochschuldidaktisches Spanungsfeld zwischen Praxisrelevanz und Befundsicherung. Wiesbaden: Springer VS.

German Association of Cities and Towns. (ed.). (2007). "Education in the City" Conference Organized by the German Association of Cities and Towns on 22/23 November 2008 in Aachen. Available at: https:/www.jena.de/fm/1727/ aachener_erklaerung.pdf

Hascher, T. (2011). "Forschung zur Wirksamkeit der Lehrerbildung," in Handbuch Forschung zum Lehrberuf, eds E. Terhart, H. Bennewitz, and M. Rothland, Martin (Münster: Waxmann), 418-441.

Heinrich, M., Faller, C., and Thieme, N. (2014). Neue alte Bildungsungleichheit durch professionskulturellen Dissonanzausgleich in differenziellen Lernmilieus? Die Dtsch. Schule 106, 31-49.
Idel, T.-S. (2016). "Zusammenarbeit als Aufgabe von Lehrkräften Professionstheoretische Überlegungen zu Erfordernissen, Zumutungen und Grenzen von Kooperation," in Professionelle Kooperation in und mit der Schule. Erkenntnisse aus der Praxisforschung, eds C. Lähnemann, A. Leuthold-Wergin, H. Hagelgans, and L. Ritschel (Greifswald: MV Publishing), 23-43.

Künzli, B. (2012). SWOT-analyse. Klassisches Instrument der Strategieentwicklung mit viel ungenutztem Potenzial. Z. Organ. 81, 126-129.

Loos, P., and Schäffer, B. (eds). (2001). Das Gruppendiskussionsverfahren Theoretische Grundlagen und empirische Anwendung. Opladen: Leske + Budrich.

Mayring, P. (2012). "Qualitative inhaltsanalyse," in Qualitative Forschung. Ein Handbuch, eds U. Flick, E. von Kardoff, and I. Steinke (Hamburg: Rowohlt), 468-475.

Prammer-Semmler, E. (2013). "Das unstillbare Verlangen nach immer mehr Praxis” - Konzeptionelle Überlegungen zu einer neuen Schulpraxis. Linz, Austria: University of Education Upper Austria.

Reh, S., and Breuer, A. (2012). "Positionierungen in interprofessionellen Teams - Kooperationspraktiken an Ganztagsschulen," in Kooperation. Aktuelle Forschung zur Kooperation in und zwischen Schulen mit anderen Partnern, eds S. Huber and F. Ahlgrimm (Münster: Waxmann), 185-202.

Rürup, M., Röbken, H., Emmerich, M., and Dunkake, I. (eds) (2015). Netzwerke im Bildungswesen. Eine Einführung in ihre Analyse und Gestaltung. Wiesbaden: Springer VS.

Schuberth, W., Speck, K., and Seidel, A. (eds). (2011). Nach Bologna: Praktika im Studium - Pflicht oder Kür? Potsdam: University Press.

Spies, A. (2016). "Im Spannungsfeld zwischen Strukturvorgaben, Konzeptentwicklung und professionellen Selbstverständnissen - Grundschule und Jugendhilfe auf dem Weg in ein kooperatives Ganztagssetting," in Professionelle Kooperation in und mit der Schule. Erkenntnisse aus der Praxisforschung, eds C. Lähnemann, A. Leuthold-Wergin, H. Hagelgans, and L. Ritschel (Greifswald: MV Publishing), 117-130.

Spies, A. (2017). "Bündnisse mit inklusivem Auftrag - Die Kooperation von Schule und Jugendhilfe in der Ganztagsschule," in (Re-) Konstruktive Inklusionsforschung. Differenzlinien - Handlungsfelder - Empirische Zugänge, eds J. Budde, A. Dlugosch, and T. Sturm (Opladen: Budrich Publishing), 33-44.

Spies, A. (2018). "Kooperation Schule - Jugendhilfe," in Kompendium Kinder- und Jugendhilfe, ed. K. Böllert (Weinheim: Juventa), 755-770.

Weber, S. M., Göhlich, M., Schröer, A., and Schwarz, J. (eds). (2014). Organisation und das Neue, Organisation und Pädagogik 15. Wiesbaden: Springer VS.

Weick, K. E. (1979). Educational organizations as loosely coupled systems. Admin. Sci. Q. 21, 1-19. doi:10.2307/2391875

Weick, K. E., and Sutcliff, K. M. (eds). (2010). Das Unerwartete managen. Hamburg: Schaeffer Poeschel.

Witzel, A. (2000). Das problemzentrierte interview. Forum Q. Soc. Res. 1, 22.

Conflict of Interest Statement: The authors declare that the research was conducted in the absence of any commercial or financial relationships that could be construed as a potential conflict of interest.

Copyright (c) 2018 de Boer, Fahrenwald and Spies. This is an open-access article distributed under the terms of the Creative Commons Attribution License (CC BY). The use, distribution or reproduction in other forums is permitted, provided the original author(s) and the copyright owner are credited and that the original publication in this journal is cited, in accordance with accepted academic practice. No use, distribution or reproduction is permitted which does not comply with these terms. 